\title{
The manifestation of cultural factors and group processes in the work of a multicultural team
}

\author{
Mikhail Leontev ${ }^{1, *}$ \\ ${ }^{1}$ Moscow State University of Civil Engineering, Yaroslavskoe shosse, 26, 129337, Moscow, Russia
}

\begin{abstract}
The relevance of the work is due to an increase in the number of multicultural teams, multicultural collectives, interactions between workers and learners, which are representatives of different nations. The globalization of the economy has led to the expansion of international relations, which means that a clash of different cultures is becoming more common, affecting different spheres of life. It is important to study the characteristics of national values and small group processes for organizing the work of a multicultural team. To this end, the study was conducted that uses and includes measurements of culture and group processes to explain the work of such teams. The results of the study confirm that culture measurements: individualism, collectivism, power distance and communication, conflict management impact on team member satisfaction. The results of this study shed light on the theoretical and practical aspects of managing multicultural teams in modern conditions and conclusions regarding their impact on team work.
\end{abstract}

\section{Introduction}

In modern conditions, the problems of multicultural teams are becoming increasingly relevant: international cooperation and associations are developing, business and intercultural relations, contacts in organizations between people with different backgrounds, experience and cultural values are extending. The cross-border movement of labor and learners due to market globalization, changes in labor laws, and cultural exchange between countries is increasing. Modern business in the context of globalization requires consideration of cross-cultural aspects for a better understanding of partners. At the same time, the volume of work in multicultural working groups and teams is increasing in educational organizations and companies [1]. These trends give rise to discussions about the impact that intercultural differences have on the work of multicultural teams [2].

The variety of definitions of intercultural differences and intercultural interaction in the scientific literature indicates the complexity of this problem. The basic principles of intercultural interaction were developed: there are no "bad" cultures; culture is known in comparison with other cultures; cultures interact with each other on the basis of equality. The role of intercultural differences is ambiguous, since they increase the ability to increase team

\footnotetext{
* Corresponding author: miillen@rambler.ru
} 
productivity and satisfaction, but at the same time, there is an increased likelihood of difficulties with establishing communication and interpersonal interaction in a team [3].

Nevertheless, the composition of the team can be analyzed not only by the social-anddemographic characteristics of its members: age, gender, education, place of residence; as well as multilevel qualities, for example, personality traits, motivation, life values and cultural values of team members, build team profiles according to these characteristics. In this work, the main emphasis is placed on cultural factors that form specific relatively stable models of thinking and behavior of individuals, according to the cultural traditions and customs in force in society. Cultural values, which can have a significant impact on team performance, have not been sufficiently considered in scientific research, in contrast to social-and-demographic parameters. Although social-and-demographic parameters may be important for teamwork, some authors have found that workers' affiliation with age and professional groups does not outweigh the influence of national culture and the influence of intra-group phenomena (cohesion, conformity, leadership) on interpersonal relations in a team [4]. In addition, the problem of intercultural interaction in teams is rarely seen as an independent factor in influencing team performance [5].

The performance of the team is influenced by various types of social interaction or group processes, including decision-making, cooperation, conflict management in a team. These processes are influenced by the cultural parameters of team members, together with other organizational environment parameters (e.g. organizational culture, team structure, management styles, motivation system), although they are not the subject of analysis in this study. It is necessary to understand how the characteristics of culture affect the social interaction in a team and the results achieved by a multicultural team.

For this purpose it is necessary to consider literature on intercultural interaction and the work of multicultural teams, which allows us to formulate hypotheses of empirical part. In this study, we interpret teams as groups of people with additional skills who are committed to a common goal for which they are responsible, who make a concerted effort and whose effectiveness is higher than the sum of individual contributions [6]. Moreover, we consider the multicultural composition of the team as an additional attribute. This study contributes by providing new hypotheses based on researches in the context of a multinational organization. Therefore, empirical work in natural groups is necessary. The feasibility of the study is determined by the following: 1) a small number of multicultural studies in large organizations and companies; 2) a small number of empirical works that link cultural values and results in multicultural teams.

Culture is one of the most sophisticated and complex concepts. However, most concepts of culture coincide in defining it as a set of values shared by individual social groups (e.g. communities, ethnic groups, classes, etc.) that influence the behaviour of people who are members of these groups and social relations, including in organizations. Culture at the macro level reflects reality external to an individual, while culture measured at the individual level reflects individuals' perception of that reality.

The relationship between culture and the communication process has been observed for a long time, it is described in detail in the G. Triandis' model. According to this model, culture influences the communication process not directly, but indirectly, through communication factors (values, norms, roles, social cognitive and affective processes, customs, etc.). Cultural characteristics influence the selection of information in the communication process, the choice of motivational strategies, methods of conflict management, social relations, self-perception, as well as affects (emotions and feelings), interaction skills. Norms, rules, roles are factors of the situation of inter-cultural interaction. They are largely due to culture, the degree to which the interlocutors understand each other, and, therefore, the success of communication itself depends on them [7]. 
Of particular importance in this series are the values of culture as the most important and deep-seated principles that determine a person's relationship with nature, society, his (her) inner circle and him(her)self. K. Klakhon and F. Strodbek defined value orientations as complex, in a certain way grouped principles that give harmony and focus to the diverse motivations of human thinking and activity in the course of solving common human problems. The ideas of K. Kluckhohn and F. Strodtbeck formed the basis of a theoretical approach to measuring Schwartz' values. In an approach to values on an individual level, Schwartz argued that values differ in the type of motivation in which they are reflected. S. Schwartz grouped values into 10 different types of human motivation (types or blocks of values). They, according to the author, determine the direction of both specific actions of an individual, and all his (her) life activity [8].

The differences in national culture identified by Hofstede through surveys of employees of international companies and some later work allowed him to highlight five independent dimensions that explain differences in terms of national culture: individualism-collectivism, power distance, uncertainty avoidance, masculinity / femininity, short- and long-term orientation. These measurements provide a detailed description of national culture, as well as manifestations of cultural characteristics at the individual level. Among the many sources of literature on features of national culture, cultural typologies and dimensions, G. Hofstede 's typology stands out because of its widespread use in all areas of cross-cultural research.

The choice for G. Hofstede typology in this study was made for the following reasons: 1) these measurements determine the extent to which people apply or avoid certain behaviors and practices in social groups (teams); 2) these measurements form the established structure and definitions widely known in the scientific community. G. Hofstede 's measurements have found wide application in cross-cultural studies, and many publications discuss their importance in the context of organizations and working groups [9].

Some previous studies have focused on the characteristics of cultures in teams and their impact on team performance, including the study by H. Wendt et al. [10]: it analyzes the cultural diversity of a team for the values of individualism and through individual perception. Our study covers: individualism and collectivism, the power distance and is aimed at expanding and deepening those works that empirically use G. Hofstede's concept. Let's look at the culture measurements in detail.

Individualism reflects the emotional independence of an individual from membership groups and collectives. Each individual seeks to be an independent unit. In individualistic cultures, it is most common for an individual 's behavior to be driven by personal goals that are mediated through different groups. The requirements for ingroup by individuals are highly segmented; the ingroup affects the behavior of people narrowly, surface, specifically, in individualistic cultures, horizontal relationships (spouses, colleagues, friends) are more important than vertical ones (parents - children). Representatives of individualistic cultures appreciate freedom in acts, independence, self-sufficiency, aspiration to differ from everyone. Human behavior is more regulated by social attitudes than social norms, personal identity prevails over social [11].

The main feature of a collectivist culture is that individuals relate their goals to the goals of the collective, community. In collectivist cultures, the individual has few membership groups, the individual's attitude to the ingroup is stable, has a great emotional attachment, individuals are proud of their group's achievements as their own. Individuals feel free and more open inside the group than outside it, the influence of a group on the behavior of individuals is broad and profound.

In collectivist cultures, the individual 's demands on a group are diffuse, the "Self" is defined in terms of group membership, and social identity is brighter than personal one; traditions, obedience, a sense of duty, the desire to "be like everyone" are of great importance. The results of studies of various collectivist cultures indicate that their representatives clearly 
distinguish between members of their group and other groups, they tend to consider events from the point of view of group affiliation [11].

The power distance characterizes the interaction of an individual and the representatives of power, means the degree to which the representatives of culture are ready to agree and support the unequal distribution of power in society. In cultures with a low level of power distance a person endowed with power is not seen as having any special rights or qualities, as surrounded by a halo of sanctity. Power is interpreted as a set of duties that the society has entrusted to fulfill one of its members for a certain time to maintain general welfare. In cultures with a high level of power distance, a person endowed with power is seen as exceptional, having special rights, largely not accountable to the majority, with a halo of sanctity. The grounds for empowering someone are often not entirely clear, mysterious [11].

Among the different processes in the small group, the communication, cooperation and conflict management processes have been chosen for this study, which cultural characteristics a greater impact on. Group processes reflect interpersonal relations between team members, results obtained by a team, satisfaction from participation in a team [12].

Studies in the field of cross-cultural collective management prove that communication between different cultures is often difficult due to national characteristics of communicative behavior, both verbal and non-verbal, direct (contacts between people and their communities) and mediated [13].

The effectiveness of communications is directly related to an understanding of the cultural, national characteristics of representatives of different nations. Effective communications in a cross-cultural field have such criteria as objectivity, accessibility (transparency), reliability, timeliness, feedback, and targeting. Cultural characteristics often determine the preferred choice of form of communication (oral or written). Thus, representatives of some cultures are more inclined to writing, others to oral, third to their combination [14].

Collaboration in a team is manifested in joint work to achieve a common goal and is important for group results. Thus, the interaction in which joint efforts are made allows us to understand how the members of a group work together and what they do to carry out the tasks assigned to them.

In turn, disagreements and conflicts accompany processes in teams. Conflict within a team occurs when tension between members becomes apparent due to real or perceived differences.

The main consequence of the group interaction taking place in the team in this study is the satisfaction of team members, that is, the degree to which people feel happy working in the team. This is important for the overall well-being and psychological functioning of an individual and affects the work avoidance, stuff turnover and probably the results obtained by the team. Thus, the satisfaction of each team member has a significant impact on collective well-being. Instrumental satisfaction is based on the satisfaction of team members with its functioning, and social satisfaction is related to the interaction between team members [14].

It is important to consider the relationship between cultural differences and group processes that affect team member satisfaction.

When the distance of power is large (people with greater authority / bosses tend to devalue the results of work and criteria of employees in lower positions), the communication process will be limited because employees are afraid to express their ideas. Moreover, since the inequality of power in organizations has two sides (authority exists only if obedience corresponds to it), employees do not consider it natural to speak out [15].

On the other hand, with a high level of collectivism, people show obvious emotional dependence on groups that tend to be strong and cohesive. The more collectivist values are manifested, the more group norms, rather than personal attitudes, determine a person's behavior. In collectivist cultures, leaders put pressure on group opinion to have consistency 
and regularity in the group. Collectivist values can therefore limit the quality of communications within a group. However, if the level of individualism is high, it will promote effective communications that will allow the job to be done well. Representatives of individualist cultures expect their personal opinions to be heard, and moreover, they do not tend to create the appearance of consent or acceptance of a group opinion if they do not share these ideas.

Cooperative behavior, cooperation within teams is also associated with shared cultural values of team members. Collectivist values force people to show more cooperative behavior towards their colleagues. Collectivists are more dependent on and confident in the group, meaning they are more predisposed to uncritical acceptance of group opinion and focused on collective responsibility than individualists. As a result, they consider individual efficiency less important than group efficiency, and subordinate their needs and desires to the requirements of the ingroup. At the same time, individualists show competition and show more limited assistance to colleagues because they were brought up in a society built on independence and individual contribution [16].

Cultural differences in a team determine the choice of conflict management methods. It should also be borne in mind that, in general, the behavior of collectivists is aimed at maintaining harmony, and the behavior of individualists is aimed at confrontation [17].

The purpose of this study was to examine the impact that culture measurements and small group processes have on team member satisfaction.

All of the above allows us to formulate the following hypotheses:

1. The higher the level of individualism in a multicultural team, the lower will be: 1) the effectiveness of communication in a team; 2) the level of cooperation in a team.

2. The higher the level of collectivism and power distance in a multicultural team: 1) the higher will be the effectiveness of communication in a team; 3) the greater will be the desire to manage conflicts in a team.

3. Satisfaction with teamwork is influenced by: communication processes, cooperation, conflict management.

\section{Materials and Methods}

The cultural composition of the team was studied by jointly interpreting two elements: 1) the cultural profile of the sample (i.e., the average value of G. Hofstede's scores for each measurement of the culture in the sample, taking into account the cultural origin of the respondents), which represents the central cultural tendency of the sample in each measurement, 2) the amount of variance of the national cultures present in the team (i.e. standard deviation), which represents the overall level of variability existing in the sample for each cultural measurement.

The study sample consisted of graduate students from a technical university (directions of training: construction, urban planning). Most of the respondents were born in Russia (93\%), all were Russian-speaking and had experience working in multicultural teams in Russia. The criterion for the multicultural team was: at least one member of the team described by the respondent should be a representative of another culture, work in it should be natural (in various sectors: construction, production, work under a contract), which involves regular interaction and the interdependence of team members (having a shared common goal of the team, each team member performs certain functions, personal contacts with other team members).

In addition, each respondent completed the questionnaire. The final valid sample was 44 people, including $67 \%$ men and 33\% women, mainly aged 21 to 32 years $(95 \%)$. When asked about working in multicultural teams, $63 \%$ of the survey participants indicated that they had worked at least once in teams of more than six people, while $27 \%$ worked in teams of 4-6 
people, and the rest in small teams. Respondents were also asked about the number of multicultural teams they worked in, and the average for the entire sample was two teams.

Further, the respondents were combined into 5 small groups for the study, 6-10 people each, so that all the teams were multicultural, they included 1-2 representatives of another culture. Each team received the task that took several days to complete and involved regular interaction and collaborative interdependent work by all team members.

The questionnaire (standardized questionnaire) was specifically designed for this study and consisted of three parts. The first part, which the respondents filled before the start of the study, made it possible to form a sample. It contains questions that allow you to identify demographic information about the respondent, his/her affiliation with the national culture, experience in multicultural teams and professional profile.

After completing the task, respondents completed the second and third parts of the questionnaire. The second part contains 30 points. The scale used to evaluate communication within the team is based on the modified T.P. Liang scale [18], with a total of 10 points. The scale used to get information about the cooperation process in the team is based on the scale proposed by M. Hoegl, H.G. Gemuenden [19], this scale consists of 8 points. The regulation of the conflict of tasks and relations was evaluated using 12 points ( 6 for each type of conflict), based on the adapted scale of intra-group conflicts presented [20].

After filling out the questionnaire, respondents were tested to measure the level of individualism / collectivism. The level of individualism / collectivism was measured using a short version of the E. Sivadas questionnaire, with a total of 16 points [21].

The study used the statistical method to reduce the dimension of the scale for measuring individual satisfaction - factor analysis with varimax rotation. This tool is to obtain a reduced number of factors that explain much of the overall variability of the observed variables; it facilitates their interpretation. Student's T-Test was used to compare the normality of variables. In addition, the statistical strength of the information was analyzed, and subsequently Pearson's correlation statistics were applied to compare the relationship between the variables and test the hypotheses formulated. Finally, for a specific relationship between group processes and team satisfaction, a follow-up analysis was conducted to identify the impact that various group processes can have on internal satisfaction compared to an individual's external satisfaction from his / her participation in the team [22].

The validity of the construct, that is, the degree to which it really measures what it should measure, was also analyzed. The validity of the construct becomes clear, given that the analysis of the main components of the factors made it possible to generalize and synthesize the observed phenomenon. In addition, substantive validity is guaranteed by both a theoretical and empirical review of the literature, as well as preliminary testing of the questionnaire. The discriminant validity is confirmed by the fact that the correlation between each pair of factors obtained at the preliminary analysis step has a correlation of 0.001 . The generalized reliability of the satisfaction scale measured with Cronbach's alpha statistics increased to 0.884 .

To clarify some survey data, interviews were conducted with some respondents. A total of 62 questionnaires were sent out, and 52 were returned with answers, which corresponds to the response rate of $84 \%$, and was analyzed. Using the questionnaire, significant information was obtained on the practice, problems and prospects of green building and architecture in the context of sustainable development in the construction industry based on the experience of respondents. Collected data included respondents' understanding of the purpose and practices of sustainable development, green building, work in development teams of green projects, practical problems of green building and architecture, the benefits arising from it, the level of importance attached to the benefits and awareness of the concept of green building. 


\section{Results}

Factor analysis conducted for satisfaction from the team revealed four factors: 1) satisfaction from participation in the team; 2) satisfaction from personal contribution to the team; 3 ) satisfaction from the results achieved by the team; 4) satisfaction with the psychological climate in the team. The first two factors relate to internal satisfaction, i.e. how satisfied the team member with his / her work, and what he / she brings to the team, while the other two relate to external satisfaction, that is, the satisfaction of the team member that he / she receives from the team. Consequently, the factors obtained combine the elements of instrumental and social satisfaction identified in scientific papers. Bilateral correlations between culture measurements and various different processes are shown in Table 1.

Table 1. The relationship of cultural measurements and group processes: average

\begin{tabular}{|l|c|c|c|c|c|c|}
\hline \multirow{2}{*}{} & \multicolumn{2}{|c|}{ Communication } & \multicolumn{2}{c|}{ Cooperation } & \multicolumn{2}{c|}{ Conflict } \\
\cline { 2 - 7 } & $\mathrm{r}$ & $\mathrm{p}$ & $\mathrm{r}$ & $\mathrm{p}$ & $\mathrm{r}$ & $\mathrm{p}$ \\
\hline Power distance & 0,325 & 0,053 & $-0,131$ & 0,452 & 0,248 & 0,015 \\
\hline Individualism & 0,146 & 0,036 & $-0,112$ & 0,427 & 0,239 & 0,014 \\
\hline Collectivism & 0,127 & 0,032 & $-0,108$ & 0,354 & 0,319 & 0,007 \\
\hline
\end{tabular}

Hereinafter: $\mathrm{r}$ - Pearson correlation coefficient, $\mathrm{p}$ - significance level.

The link between cultural measurements and communication and conflict management processes has been partially confirmed.

With regard to the relationship between group processes and results, apart from cooperation, other types of group processes (communication, conflict management) were reflected in the satisfaction of team participation (Table 2). More specifically, there is a link between communication processes (involving team members in discussions), conflict management with internal and / or external satisfaction.

Table 2. The relationship between group processes and team satisfaction.

\begin{tabular}{|l|c|c|c|c|c|c|c|c|}
\hline & \multicolumn{2}{|c|}{1} & \multicolumn{2}{|c|}{2} & \multicolumn{2}{|c|}{3} & \multicolumn{2}{|c|}{4} \\
\cline { 2 - 9 } & $\mathrm{r}$ & $\mathrm{p}$ & $\mathrm{r}$ & $\mathrm{p}$ & $\mathrm{r}$ & $\mathrm{p}$ & $\mathrm{r}$ & $\mathrm{p}$ \\
\hline Communication & 0,349 & 0,041 & 0,228 & 0,924 & 0,011 & 0,998 & 0,114 & 0,051 \\
\hline Cooperation & 0,027 & 0,875 & 0,181 & 0,323 & 0,047 & 0,797 & 0,025 & 0,678 \\
\hline $\begin{array}{l}\text { Conflict } \\
\text { management }\end{array}$ & 3,358 & 0,037 & 0,449 & 0,007 & 0,103 & 0,006 & 0,304 & 0,024 \\
\hline
\end{tabular}

Note. 1 - satisfaction from participation in the team work; 2 - satisfaction from personal contribution to the team; 3 - satisfaction from the results achieved by the team; 4 satisfaction with the psychological climate in the team

\section{Discussion}

Communicative processes have a direct and positive impact on the achievement of results by the team. It seems obvious that poor communication in a team leads to failures in the work. In fact, an effective communication process allows team members to be informed on issues that are relevant to the successful completion of tasks, that is, to set specific goals, change working methods, etc. Thus, open and intensive communication, which facilitate quick access to the necessary information, will increase team productivity, increase the satisfaction of team members [23].

The hypotheses of the study were partially confirmed. 
According to the results obtained, the power distance had a greater influence on group processes than individualism / collectivism (see Table 1). This is in line with the opinion of G. Hofstede [24]: the more unevenly distributed the power (the greater the power distance), the more intense the differences between people become and the more the bi-directional exchange of information will be presented.

Collectivism, according to the results obtained, was more correlated with conflict management than with individualism (see Table 1), which can be explained by the great desire of collectivists for intragroup harmony.

The results show that in our sample, cooperation as an independent variable is unrelated to results. However, a theoretical review has clearly shown that the processes of cooperation and conflict management are related to the cultural measurements that are described in our study. Laboratory studies were able to confirm that cooperation is crucial for the team to achieve performance and is therefore included as an independent variable in various models. However, its independent influence was not assessed in the context of the team. A joint link was found between the communication and cooperation factor within the team and the efficiency achieved by the team. Empirical works of other authors do not establish the independent influence of cooperation, but only together with communication in a team [25]. In addition, the interaction of a team member in the process of cooperation facilitates getting help with tasks, training knowledge and skills available in the team, and better integration of colleagues, which can improve the instrumental and social satisfaction of team members.

The psychological climate is an important component of the effective functioning of a team, as it affects the personal productivity of employees, the coherence and synergy of a team. The creating and maintaining a psychological climate is crucial to team outcomes. The climate of a team is most often threatened by conflict [1]. In this regard, satisfaction with the psychological climate in the team correlates as much as possible with conflict management (see Table 2).

Psychological climate is an important component of effective functioning of the team, as it affects personal productivity of employees, coherence and synergy of the team. In connection with this... Argues that creating and maintaining a psychological climate is crucial to team outcomes. The climate of the collective is most often threatened by conflict. Therefore, satisfaction with the psychological climate in the team correlates as much as possible with conflict management (see Table 2).

The role played by conflict within a small group and team is very ambiguous. However, the adoption of the conflict makes it possible to perceive its important contribution, which promotes to functioning and group results [5], while at the same giving rise the need for adequate management it. In fact, it is unlikely that a conflict-avoiding team will achieve a high level of results. Given the interest in knowing the impact of cultural aspects on team outcomes, in this work we are not trying to find out the positive or negative role of conflict, we are trying to confirm that managing it affects the instrumental and social satisfaction of team members. In this regard, we should emphasize that conflict management involves recognition of its existence, as well as the search for solutions that ultimately bring positive benefits in the development of an appropriate working environment and lead to the satisfaction of team members.

According to the results of the work carried out in teams, the transfer of information that characterizes the communication process, as well as conflict management processes, is important in the processes taking place in the teams, as suggested J. Gallenkamp [5]. According to the results, the two above-mentioned processes are largely associated with satisfaction from participation in the team (see Table 2). The information flow within the team is important for its members to be proud of belonging to this team and wish to continue to work together. In addition, communication and conflict management were positively associated with satisfaction with their contribution to the team (see Table 2), which depends 
on how productively he / she acts in the team, during the discussion, in finding a solution to the problems. Satisfaction with the results achieved by the team poorly correlated with group processes, which may mean a low interest in obtaining a group-wide result, a greater focus on communication in the team (see Table 2). So, the communication and conflict management process generally correlated with team satisfaction.

\section{Conclusions}

The results of the study confirm that culture measurements and group processes impact on team member satisfaction. Culture measurements are positively associated in teams with communication and conflict management, which have an impact on satisfaction (internal and external) of the team.

This paper contributes to the field of intercultural research, as not enough research is carried out with the participation of multicultural teams in organizations. From a practical point of view, in any organization in which teams work, the question can be raised about the design of multicultural teams with suitable cultural parameters. This will make it possible to achieve the desired results more effectively and faster, in particular, improve communication [26] and increase team productivity. Although designing such a team composition is not always possible, according to E. Autio et al. [27], in practice, cultural dimensions can be used to form teams and improve team performance.

These findings may be of interest not only for organizations in which teams working, but also for multicultural organizations in the context of working groups that are widely used.

A number of important issues can be discussed in more detail in future research papers: 1) applying cultural measurements and the designing a team to perform tasks of a certain type; 2) consideration of the influence of other cultural dimensions on the work of a multicultural team; 3 ) consideration of the features of the process of preparation, discussion and decision-making in a multicultural team; 4) expanding knowledge of the link between leadership, cohesion and other group processes.

\section{References}

1. M. Mekonnen. Multicultural Team Management in the Context of a Development Work, Journal of Sustainable Development, 9 (1), 8-13 (2016)

2. G. K. Stahl, M. Maznevski, A. Voigt, K. Jonsen. Journal of International Business Studies 41, 690-709 (2010)

3. B. L. Kirkman, J. L. Cordery, J. Mathieu, B. Rosen, M. Kukenberger. Human Relations 66 (3), 333-362 (2013)

A. Lisak, M. Erez. Journal of World Business 50 (1), 3-14 (2015)

4. J. Gallenkamp. Conflict, Culture, and Management - Antecedents of Performance in Virtual Teams. (Lulu.com, 2011)

5. J. Adair. Effective Team Building: How to make a winning team. (London: Pan Macmillan, 2009)

6. H. C. Triandis. Cultural Intelligence in Organizations, Group \& Organization Management 31 (1), 20-26 (2006)

7. S. H. Schwartz. An Overview of the Schwartz Theory of Basic Values, Online Readings in Psychology and Culture 2 (1), 2012. Open access: https://doi.org/10.9707/2307$\underline{0919.1116}$ 
8. K. Leung, S. Ang, M. L. Tan. Intercultural Competence, Annual Review of Organizational Psychology and Organizational Behavior 1, 489-519 (2014)

9. H. Wendt, M. C. Euwema, I. J. Hetty van Emmerik. The Leadership Quarterly 20 (3), 358-370 (2009)

10. G. Hofstede. Dimensionalizing Cultures: The Hofstede Model in Context, Online Readings in Psychology and Culture 2 (1), 2011. Open access: https://doi.org/10.9707/2307-0919.1014

11. P. Hinds, L. Liu, J. Lyon. Putting the Global in Global Work: An Intercultural Lens on the Practice of Cross-National Collaboration, The Academy of Management Annals 5 (1), 135-188 (2011)

12. E. Badzińska. Journal of Intercultural Management 9 (3), 29-44 (2017)

13. S.B.F. Paletz, A. Sumer, E. Miron-Spektor. International Journal of CoCreation in Design and the Arts Volume 14 (2), 98-114 (2018)

14. J. Hornikx, R. le Pair. Journal of Global Marketing, 30 (4), 228-237 (2017)

15. L. Ni, Q. Wang, B.-L. Sha. Intercultural Public Relations: Theories for Managing Relationships and Conflict with Strategic Publics. (NY: Routledge, Taylor \& Francis, 2018)

16. T. Patel. Cross-Cultural Management. A Transactional Approach. (NY: Routledge, 2014)

17. T. P. Liang, J. Wu, J. J. Jiang, G. Klein. International Journal of Project Management 30 (6), $731-739$ (2012)

18. M. Hoegl, H. G. Gemuenden. Organization Science 12 (4), 435-449 (2001)

19. K. A. Jehn, L. Greer, S. Levine, G. Szulanski, Group Decision and Negotiation 17, 465 495 (2008)

20. E. Sivadas, N. T. Bruvold, M. R. Nelson. Journal of Business Research 61, 201-210 (2008)

21. K. McCormick, J. Salcedo. SPSS Statistics for Data Analysis and Visualization. (Indianapolis, Wiley \& Sons, 2017)

22. E. T. G. Wang, J. Y. T. Chang, J. J. Jiang, G. Klein, International Journal of Project Management 29 (2), 146-154 (2011)

23. G. Hofstede. The GLOBE debate: Back to relevance, Journal of International Business Studies, 41 (8), 1339-1346 (2010)

24. S. Beugelsdijk, C. Welzel. Dimensions and Dynamics of National Culture: Synthesizing Hofstede With Inglehart, Journal of Cross-Cultural Psychology 49 (10), 1469-1505 (2018)

25. S. W. Congden, A. V. Matveev, D. E. Desplaces, Journal of Comparative International Management 12 (2), 73-89 (2009)

26. E. Autio, S. Pathak, K. Wennberg. Journal of International Business Studies 44 (4), 334-362 (2013) 